\title{
Kateter Enfeksiyonlarına Alternatif Çözüm: Kilit Tedavisi
}

\section{Alternative Solution to Catheter Infections: Lock Therapy}

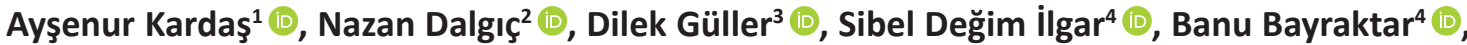 \\ Ömer Naci Tabakçı ${ }^{5}$ (i)
}

\begin{abstract}
${ }^{1}$ Sağlık Bilimleri Üniversitesi, Şişli Hamidiye Etfal Eğitim ve Araştırma Hastanesi, Çocuk Sağlığı ve Hastalıkları Kliniği, İstanbul, Türkiye ${ }^{2}$ Sağlık Bilimleri Üniversitesi, Şişli Hamidiye Etfal Eğitim ve Araştırma Hastanesi, Çocuk Enfeksiyon Hastalıkları Kliniği, İstanbul, Türkiye ${ }^{3}$ Sağlık Bilimleri Üniversitesi, Şişli Hamidiye Etfal Eğitim ve Araştırma Hastanesi, Çocuk Gastroenteroloji Kliniği, İstanbul, Türkiye ${ }^{4}$ Sağlık Bilimleri Üniversitesi, Şişli Hamidiye Etfal Eğitim ve Araştırma Hastanesi, Tıbbi Mikrobiyoloji, İstanbul, Türkiye

${ }^{5}$ Sağlık Bilimleri Üniversitesi, Şişli Hamidiye Etfal Eğitim ve Araştırma Hastanesi, Radyoloji Kliniği, İstanbul, Türkiye
\end{abstract}

ORCID ID: A.K. 0000-0003-1764-0509; N.D. 0000-0002-6516-8897; D.G. 0000-0002-8306-5445; S.D.i. 0000-0001-9691-6539; B.B. 0000-0002-3128-0581; Ö.N.T. 0000-0001-8791-2536

Atff/Citation: Kardas A, Dalgic N, Guller D, Değim İlgar S, Bayraktar B, Tabakci, ON. Kateter enfeksiyonlarına alternatif çözüm: Kilit tedavisi. Çocuk Dergisi Journal of Child 2020;20(3):124-126. https://doi.org/10.26650/jchild.2020.3.772803

Öz

Uzun süreli kalıcı kateter kullanımının en önemli komplikasyonu kateter enfeksiyonlarıdır. Infectious Diseases Society of America (IDSA) koagülaz negatif stafilokok, S.aureus ve gram (-) ilişkili kateter enfeksiyonlarında kateter değişimi mümkün değilse sistemik tedavi ve kateter kilit tedavisinin birlikte verilmesini; fungal enfeksiyonlarda ise kateterin değişimini önermektedir. Ancak kısa barsak sendromu, konjenital diare bozuklukları gibi özel hasta gruplarında Candida ilişkili kateter enfeksiyonları sık görülmektedir. Bu durum sürekli kateter değişimleri ve komplikasyonlarına neden olmakta, hastanelerde büyük maliyet kaybı oluşturmaktadır. Burada NEUROG3 gen defekti, konjenital intestinal malabsorbsiyon sendromu tanılı yaşamını parenteral nutrisyon ile idame ettiren iki yıl dokuz aylık kız hastada liposomal amfoterisin B kilit ve sistemik tedavisi uygulanarak $C$. glabrata ilişkili kateter enfeksiyonunun tedavi edildiği başarılı bir olgu sunulmuştur.

Anahtar Kelimeler: Liposomal amfoterisin B, liposomal kilit tedavisi, fungal enfeksiyonlar, NEUROG3

\section{ABSTRACT}

One of the main complications of long-term use of permanent catheters is infection of the catheter. Guidelines issued by the Infectious Diaseases Society of America (IDSA) recommend the additon of antibiotic lock therapy to parenteral antibiotic therapy for tunneled or implantable catheter-associated infections caused by coagulase-negative Staphylococcus, $S$ aureus, and gram-negative rods when removal of the catheter is not an option. However, IDSA guidelines strongly recommend removal of the catheter if possible in patients with catheter-associated infections secondary to Candida. However, Candida-associated catheter infections are common in certain high-risk patient groups including those with short bowel syndrome and congenital diarrheal disorders. Such situationsmay necessitate frequent ghange of catheters along with a host of other complications, resulting in huge loss of revenue to hospitals as well as inconvenience to patients. Here, we present a case in which $C$. glabrata-associated catheter infection was successfully treated by applying liposomal amphotericin B lock along with systemic antifungal treatment. The patient was a young girl aged 2 years and 9 months having Neurogenin-3 (NEUROG3) gene defect associated with congenital intestinal malabsorption syndrome.

Keywords: Liposomal amphotericin B, liposomal lock therapy, fungal infections, NEUROG3

ve mortalite nedeni olan kateter enfeksiyonlarıdır (1). Kateter kolonizasyonu ve enfeksiyonuna en sık neden olan organizmalar; koagülaz negatif stafilokoklar (özellikle Staphylococcus epidermidis), enterokoklar, Staphylococcus aureus ve Candida'dır (2). Literatürde seçilmiş hastalarda, kateter ile ilişkili kan dolaşımı enfeksiyonlarında, santral venöz kateteri kurtarmak için

Sorumlu Yazar/Corresponding Author: Ayşenur Kardaş E-mail: draysenurkardas@gmail.com

Başvuru/Submitted: 23.07.2020 • Kabul/Accepted: 07.09.2020 
antibiyotik kilit tedavisi uygulanması denenmiştir. Kilit tedavisi; kateterin seçilen antimikrobiyal ajan ile kateter lümeninde kolonize olan enfeksiyöz ajanlardan temizlenmesi için bir süre bekletilmesi şeklinde uygulanır. Amerika Enfeksiyon Hastalıkları Topluluğu (Infectious Diseases Society of America, IDSA); koagülaz negatif stafilokok, S. aureus ve gram (-) çomak ilişkili kateter enfeksiyonlarında kateter değişimi mümkün olmadığında sistemik tedavi ve kateter kilit tedavisinin birlikte verilmesini; fungal kateter enfeksiyonlarında ise kateterin çıkarılmasını ve seçilen antifungal ajanla on dört gün süreyle sistemik tedavisini önermektedir (2). Ancak kısa barsak sendromu, konjenital diare bozuklukları gibi özel hasta gruplarında Candida ilişkili kateter enfeksiyonları sık görülmektedir. Bu durum, sürekli kateter değişimlerine ve komplikasyonlarına neden olmakta aynı zamanda hastanelerde büyük maliyet kaybı oluşturmaktadır. Kateteri çıkarmadan sadece sistemik antifungallerle tedavi edilen kandidemili hastalarda kateter kurtarma oranları çok düşüktür. Kateterin korunduğu başarılı olan tedavilerde kullanılan yaklaşım; seçilen antifungal ajan ile birlikte günde 8-12 saat süren kilit tedavisi ve sistemik tedaviden oluşmaktadır (3).

Uzun süreli kateter kullanımı gerektiren hastalarda hayat kurtaran ve yaşam kalitesini artıran kateter kilit tedavisi özellikle çocukluk yaş grubunda total parenteral nütrisyon (TPN) bağımlı hastaların evde takip ve tedavisinde çı̆̆ır açmıştır. Bunlardan biri olan konjenital diare bozuklukları, yaşamın başlangıcında hayat tehdit eden diareler ile ortaya çıkan nadir bir enteropatiler grubudur (4). Bu grubun bir üyesi olan enterik anendokrinoziste; Neurogenin-3 (NEUROG3) genindeki resesif kalıtsal mutasyonlara bağlı bağırsak enteroendokrin hücrelerinin eksikliği, konjenital malabsorptif ishal, büyüme gelişme geriliği görülür (4). Hastalar hayat boyu parenteral nutrisyona ihtiyaç duyar. Burada; NEUROG3 gen mutasyonu nedeniyle konjenital intestinal malabsorbsiyonu olan, Candida ilişkili tekrarlayan kateter enfeksiyonları bulunan bir hastada, kateter çıkarılmadan liposomal amfoterisin B kilit tedavisi kullanılarak kateterin kurtulabildiği başarılı bir olgu sunulmaktadır.

\section{OLGU}

Iki yıl dokuz aylık kız hasta; NEUROG3 gen defekti, konjenital barsak malabsorbsiyonu tanılarıyla çocuk enfeksiyon servisimizde takip edilmekteydi. Hastanın; on yedi günlükken şiddetli diare, dehidratasyon ve metabolik asidoz nedeniyle yoğun bakım ihtiyacı olmuş, on yedi ay boyunca yoğun bakım ünitesinde takip edilmişti. Bu süreçte diğer enfeksiyöz, immünolojik ve metabolik nedenler dışlandıktan sonra yurtdışına gönderilen hekzon gen analizi ile NEUROG3 gen defekti tanısı almışt. Hastanın prenatal ve natal takipleri sorunsuz; $2900 \mathrm{gr}$ (15. persantil) term doğum öyküsü mevcuttu. Hastanemize başvurusunda boyu 76 $\mathrm{cm}(<3 p)$, kilosu $8 \mathrm{~kg}(<3 p)$ idi. Aynı gen defektine sahip bir kardeşi , anne baba arasında birinci derece kuzen evliliği vardı.

Hastanın servisimize kabulündeki tetkiklerinde; hemoglobin $10,3 \mathrm{~g} / \mathrm{dL}$, beyaz küre $19390 / \mathrm{mm}^{3}$ nötrofil $4030 / \mathrm{mm}^{3}$, trombosit 346.000/ $\mathrm{mm}^{3}$, prokalsitonin 0,28 ug/L ( 0-0,12 ug/L), C-reaktif protein $5 \mathrm{mg} / \mathrm{L}$ (0-5 mg/L) idi. Dış merkez epikrizinden hastanın beş gündür ateşinin olmadığı, son alınan kan kültürü ve katater kültüründe $C$. parapsilosis üremesi olduğu öğrenilerek hastanın kullanmakta olduğu antibioterapileri kesildi. Kateteri çıkarılıp, kan kültürü alınarak mikafungin tedavisi $2 \mathrm{mg} /$ $\mathrm{kg} / \mathrm{gün}$ olarak periferik damar yolundan başlandı. Tedaviden bir hafta sonra klinik seyrinin iyi olduğu ve kan kültüründe üreme olmadığı gözlenerek santral venöz kateter takıldı. Hastanın servisimizde takip edildiği süre içinde; Staphylococcus epidermidis, Enterococcus faecium, Klebsiella pneumonia, C. parapisilosis etkenlerinin ürediği kateter enfeksiyonları nedeniyle dört kez kateter değişimi oldu. Son kateter enfeksiyonu sonrası, devam eden süreçlerde uygulanabilecek olan antibiyotik kilit tedavisi için port kateteri yerine girişimsel radyoloji tarafindan Hickman kateteri takıldı. Hickman kateteri takılmasından iki hafta sonra hastanın ateşi olması üzerine alınan tam kan sayımında: hemoglobin: 9,6 g/dL, beyaz küre: $3970 / \mathrm{mm}^{3}$, nötrofil: $1680 /$ $\mathrm{mm}^{3}$, trombosit: $178.000 / \mathrm{mm}^{3}$, C-reaktif protein: $10 \mathrm{mg} / \mathrm{L}(0-5$ $\mathrm{mg} / \mathrm{L}$ ) idi. Sepsis düşünülerek kan ve kateter kültürleri alındı. Daha önceki antibiyogramları göz önüne alınarak ampirik olarak sefaperazon-sulbaktam $150 \mathrm{mg} / \mathrm{kg} /$ gün ve flukonazol $12 \mathrm{mg} /$ $\mathrm{kg}$ /gün başlandı. İzleminde genel durumunda iyileşme gözlenmemesi üzerine kan ve kateter kültürleri tekrarlanarak tedavisine vankomisin eklendi. Hastanın ilk alınan kan kültürlerinde vankomisine dirençli enterokok ürediği bildirilmesi üzerine vankomisin tedavisi kesilerek tedaviye linezolid eklendi. Hastanın ateşlerinin dört gündür aralıklı seyretmesi ve kliniğinin düzelmemesi nedeniyle fungal enfeksiyon olabileceği düşünülerek kan ve kateter kültürleri tekrarlandı. Flukonazol tedavisi kesilip, vorikonazol $18 \mathrm{mg} / \mathrm{kg} /$ gün başlandı. Kateter kültüründe maya üremesi olduğu bildirildi. Kateter kan kültüründe üreyen maya kolonileri Sabouraud Dekstroz Agar (SDA) besiyerine ekildi. SDA besiyerinde üreyen maya izolatları MALDI-TOF MS (Bruker Daltonics, Almanya) ile C. glabrata (skor 2,1) olarak isimlendirildi. Maya duyarlılık testleri Sensititre Yeast One Panel (Trek Diagnostic Systems, ABD) ile yapıldı ve CLSı M60'a göre değerlendirildi. C. glabrata üremesi olduğu gözlendi. Antifungal duyarlılık testinde liposomal amfoterisin B duyarlı olan hastanın tedavisi, liposomal amfoterisin B ile sistemik tedavi ve kilit tedavisi olarak planlandı. Günlük 12 saat parenteral nutrisyonu tamamlandıktan sonra kateter lümenine, $2500 \mathrm{IU} / \mathrm{ml}$ heparin ve $2 \mathrm{mg} / \mathrm{ml}$ konsantrasyonda liposomal amfoterisin B içeren $2 \mathrm{ml}$ lik izotonik salin verildi. Eş zamanlı liposomal amfoterisin B $5 \mathrm{mg} / \mathrm{kg} /$ gün sistemik tedavi başlandı. Tedavi sırasında gün aşırı kateter ve kan kültürü alındı. Tedavinin 8 . gününde alınan kan ve kateter kültürlerinde üreme olmadı. Kateter tedavisi 14 gün, sistemik tedavisi ise 21 güne tamamlandı. Hasta evde TPN almak üzere mevcut kateteriyle taburcu edildi. Üç aylık poliklinik izleminde herhangi bir enfeksiyon gözlenmedi.

\section{TARTIŞMA}

Konjenital diare ve enteropatiler hayatın başlangıcında şiddetli diareler ile kendini gösterir. Bu grubun ender bir sebebi olan enterik anendokrinozis, NEUROG3 genindeki kalıtsal defektlere bağı ı barsakta enteroendokrin hücrelerin belirgin azalması ile karakterizedir. NEUROG3 defekti aynı zamanda pankreas endokrin hücrelerini de etkiler (5). Hastalarda diyabet, pankreas endokrin hücrelerinin etkilenmesine bağlı yenidoğan dönemi de dahil olmak üzere bebeklik veya çocukluk çağında herhangi 
bir yaşta ortaya çıkabilir (5). Hastalar ömür boyu parenteral nutrisyona ihtiyaç duyar. Bu ihtiyaç uzun süreli kalıcı kateter kullanımına ve kateter enfeksiyonlarına neden olmaktadır.

Yapılan çalışmalar kateter enfeksiyonlarının tek başına sistemik antibioterapi ile tedavi edilmesinin \%67 oranında kurtulma sağladığını göstermiştir (2). Kilit tedavisi ve sistemik tedavinin birlikte kullanılması ise bu oranı anlamlı ölçüde artırmıştır. Antibiyotik kilit tedavisi kateterin lümenine daha yüksek konsantrasyonda ilaç verilebilmesi, kateter değişim komplikasyonlarını ve maliyetlerini azaltma gibi avantajları da beraberinde getirmiştir (3). Fungal kateter enfeksiyonlarında standart tedavi kateterin çıkarılması olsa da olgumuzdaki gibi uzun süreli TPN alan tekrarlayan kateter enfeksiyonları olan hastalarda kilit tedavisinin kullanılması çığır açmıştır.

Literatürde hemodinamik olarak stabil olan, seçilmiş hastalarda liposomal amfoterisin B kilit tedavisinin başarıyla uygulandığı vakalar bulunmaktadır. Castagnola ve arkadaşlarının C.parapsilosis kateter enfeksiyonu bulunan bir infant liposomal amfoterisin B kilit tedavisi ile tedavi etmesi literatürdeki ilk vakadır (6). Daha sonrasında Buckler ve arkadaşlarının yayınladığı vaka serisinde, Candida kateter enfeksiyonu olan alt hastanın dördü liposomal amfoterisin B kilit tedavisi ile başarılı bir şekilde tedavi edilmiştir (3). McGhee ve arkadaşlarının yayınladığı çocuk hastaları içeren prospektif bir çalışmada ise on üç vakaya liposomal amfoterisin B kilit tedavisi uygulanmış ve on vakada başarılı olduğu gözlenmiştir (1). Bizim olgumuzda da, liposomal amfoterisin B kilit tedavisi ve sistemik tedavi birlikte verilerek kateter kurtarma tedavisi başarıyla sağlanmıştır. Hastamız tedavi sonrası taburcu edilip üç ayda bir poliklinik kontrolleriyle takip edilmiştir. Hastanın parenteral nutrisyon alımına evde devam ederek poliklinik kontrollerine gelmesi, yaşam kalitesini önemli oranda artırmıştır. Hayat boyu parenteral nutrisyon kullanan hastalarda kilit tedavisinin başarıyla uygulanması umut vadedici olup hastaların evde izlemine olanak sağlamaktadır.

Hakem Değerlendirmesi: Dış bağımsız.

Yazar Katkıları: Çalışma Konsepti/Tasarım- A.K., N.D., Ö.N.T.; Veri
Toplama- D.G.; Veri Analizi/Yorumlama- S.D.İ., B.B.; Yazı Taslağı- A.K., N.D.; İçeriğin Eleştirel İncelemesi- Ö.N.T., S.D.I., B.B., D.G.; Son Onay ve Sorumluluk- A.K., N.D., D.G., S.D.I., B.B., Ö.N.T.; Süpervizyon- N.D.

Çıkar Çatışması: Yazarlar çıkar çatışması beyan etmemişlerdir.

Finansal Destek: Yazarlar finansal destek beyan etmemişlerdir.

Peer Review: Externally peer-reviewed.

Author Contributions: Conception/Design of Study- A.K., N.D., Ö.N.T.; Data Acquisition- D.G.; Data Analysis/Interpretation- S.D.I., B.B.; Drafting Manuscript- A.K., N.D.; Critical Revision of Manuscript- Ö.N.T., S.D.I., B.B., D.G..; Final Approval and Accountability- A.K., N.D., D.G., S.D.I., B.B., Ö.N.T.; Supervision- N.D.

Conflict of Interest: Authors declared no conflict of interest.

Financial Disclosure: Authors declared no financial support.

\section{KAYNAKLAR}

1. McGhee W, Michaels MG, Martin JM, Mazariegos GV, Green M. Antifungal lock therapy with liposomal amphotericin B: A prospective trial. J Pediatric Infect Dis Soc 2016;5(1):80-4.

2. Mermel LA, Farr BM, Sherertz RJ, Raad II, O'Grady N, Harris JS, et al. Guidelines for the management of intravascular catheter-related infections. Clin Infect Dis 2001;32(9):1249-72.

3. Buckler BS, Sams RN, Goei VL, Krishnan KR, Bemis MJ, Parker $D P$, et al. Treatment of central venous catheter fungal infection using liposomal amphotericin-B lock therapy. Pediatr Infect Dis J 2008;27(8):762-4.

4. Germán-Díaz M, Rodriguez-Gil Y, Cruz-Rojo J, Charbit-Henrion F, Cerf-Bensussan N, Manzanares-López Manzanares J, et al. A new case of congenital malabsorptive diarrhea and diabetes secondary to mutant neurogenin-3. Pediatrics 2017;140(2):e20162210.

5. Azab B, Dardas Z, Rabab'h O, Srour L, Telfah H, Hatmal MM, et al. Enteric anendocrinosis attributable to a novel Neurogenin-3 variant. Eur J Med Genet 2020;63(9):103981.

6. Castagnola E, Marazzi MG, Tacchella A, Giacchino R. Broviac catheter-related candidemia. Pediatr Infect Dis J 2005;24(8):747. 